\title{
TUMORES NEUROGENICOS DE NERVIOS PERIFERICOS: ESTUDIO POR IMAGENES
}

\section{Dra. Sara Muñoz Ch.}

Departamento de Radiología Clínica Las Condes

\begin{abstract}
The article review the images of benign and malignat tumors of the peripheral nerves with emphasis in MRI and ultrasound.
\end{abstract}

Key words: Imaging, Peripheral nerves, Tumors.

Resumen: Se revisa la manifestación en imágenes de los tumores benignos y malignos que afectan los nervios periféricos. Se destacan sus características en diferentes modalidades en especial ultrasonografía y resonancia magnética.

Palabras claves: Nervio periférico, Tumor, Imágenes.

\section{Introducción}

Los tumores de nervios periféricos pueden ser no neoplásicos o neoplásicos, originándose estos últimos en las vainas nerviosas. Arthur Purdy Stout (1885-1967) fue pionero en la comprensión de su histogénesis, ya que fue quien identificó la célula de Schwann como el principal elemento constituyente, tanto en tumores benignos como malignos ${ }^{(1)}$.

El diagnóstico debe considerar la historia clínica, el examen físico y la evaluación imagenológica. La historia y el examen físico son fundamentales ya que muchas veces la presentación clínica es como una masa de partes blandas. La anamnesis debe incluir los antecedentes del paciente, la presencia o no de sintomatología (dolor, signo de Tinel, etc), el tipo de crecimiento de la tumoración, la existencia de masa única o múltiple. El examen físico debe buscar dirigidamente ciertos elementos como por ejemplo manchas café con leche características de la neurofibromatosis, o tipo de masa a la palpación.

\section{Diagnóstico por imágenes}

El diagnóstico incluye la evaluación imagenológica siendo los exámenes más utilizados el ultrasonido (US), la tomografía computada (TC) y la

Muñoz S. Tumores Neurogénicos de Nervios Periféricos: Estudio por imágenes. Rev Chil Radiol 2003; 9: 124-136 Correspondencia: Dra. Sara Muñoz Ch.

Clínica Las Condes. Lo Fontecilla 441

Sara.munoz@entelchile.net resonancia magnética $(\mathrm{RM})$. Las características imagenológicas pueden sugerir muchas veces el diagnóstico y su análisis en conjunto con los antecedentes clínicos y el examen físico lo hacen más preciso.

Los signos imagenológicos son un reflejo de las características histológicas del tejido neurogénico del cual derivan ${ }^{(2)}$.

Los nervios periféricos tienen dos elementos de soporte: el estroma conectivo y las células de Schwann que envuelve los axones en diferentes grados. Cada nervio periférico está rodeado por un denso tejido conectivo o vaina llamada epineuro. En el interior del nervio, los grupos de axones están separados por un estroma fibroso, el perineuro. La apariencia normal de un nervio periférico tanto en US como en RM se correlaciona estrechamente con estas estructuras (Figura 1).

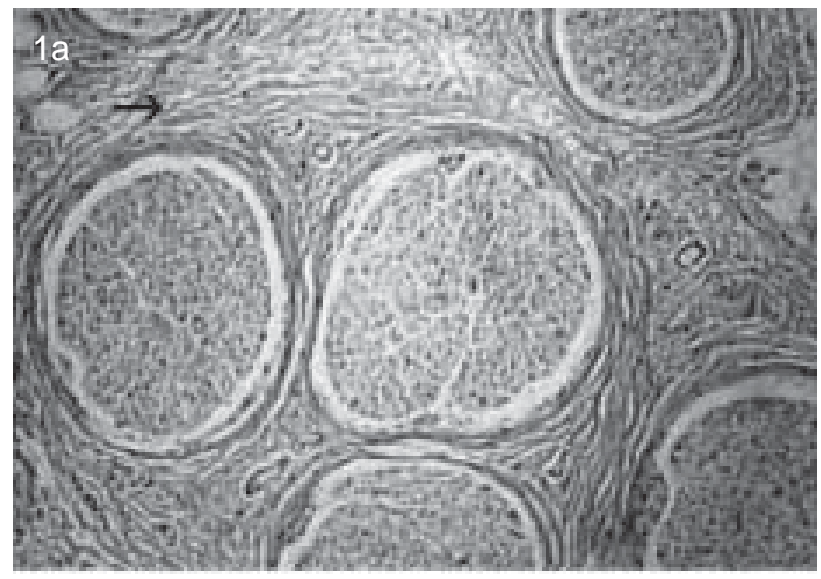

Figura 1 a-e. a: Corte histológico de nervio periférico: Perineuro (flecha negra) y epineuro rodeando el conjunto de axones. b: Microfotografía electrónica de nervio periférico: Perineuro (flecha negra). c: RM T1 Corte axial Nervio ciático (flecha). d: US de nervio mediano en corte longitudinal (entre flechas). e: US de nervio mediano en corte transversal (flecha).

\section{Clasificación}

A. Tumores benignos: Se incluyen en estos al Neuroma de Morton, el neuroma traumático, el ganglión de vaina nerviosa, el fibrolipoma neural y los 

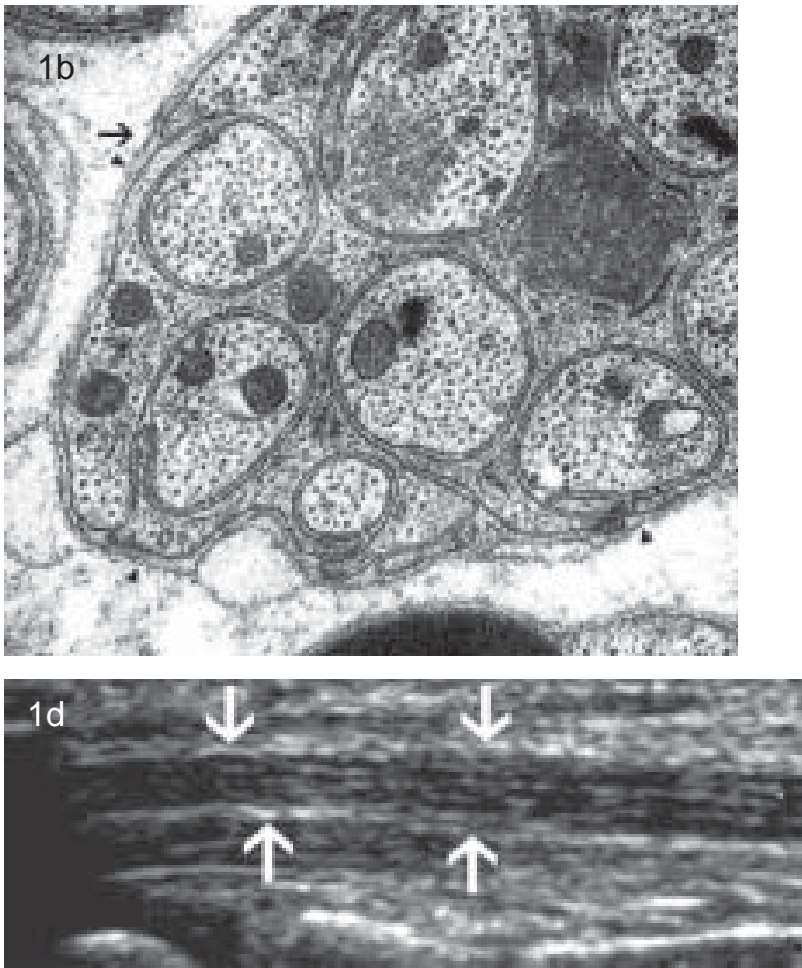
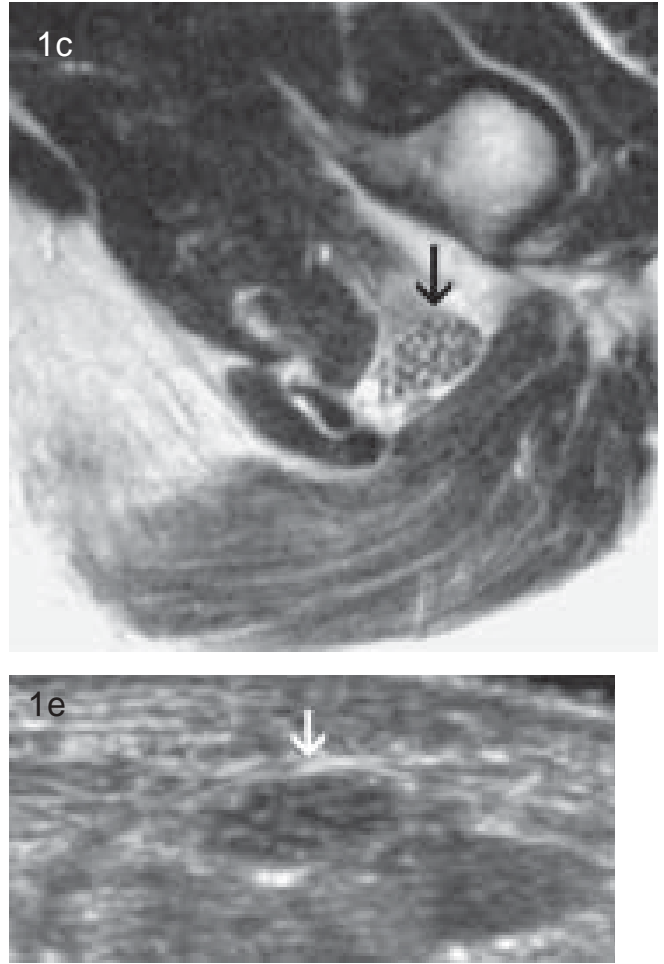

Figura 1 a-e. a: Corte histológico de nervio periférico: Perineuro (flecha negra) y epineuro rodeando el conjunto de axones. b: Microfotografía electrónica de nervio periférico: Perineuro (flecha negra). c: RM T1 Corte axial Nervio ciático (flecha). d: US de nervio mediano en corte longitudinal (entre flechas). e: US de nervio mediano en corte transversal (flecha).

tumores de la vaina neural: Schwannoma y Neurofibroma B. Tumores malignos: Schwannoma maligno y Tumor Triton.

\section{A. Tumores benignos}

A 1.- Neuroma de Morton: Descrito en 1876 por Thomas Morton (2), aunque ya había sido reportado un año antes por Durlacher ${ }^{(3)}$ corresponde a una tumoración no neoplásica que afecta un nervio plantar digital a nivel de la cabeza de los metatarsianos. Representa una fibrosis perineural asociada a una reacción inflamatoria de etiología no aclarada ${ }^{(2,3)}$. Se ha sugerido que la lesión estaría causada por una compresión neural contra el ligamento intermetatarsiano especialmente cuando se carga el antepié, situación que se produce con el uso de zapatos altos, lo que explicaría la gran diferencia de presentación por sexo (18:1 F:M). Su localización más frecuente es entre el tercer y cuarto metatarsiano. Clínicamente se caracteriza por dolor y sensación de corriente frente a la compresión, aunque no todos son sintomáticos ${ }^{(3)}$.

En el estudio por imágenes la Rx simple es invariablemente normal, sin embargo, debe realizarse para descartar otras causas de metatarsalgia.

EI US es muy utilizado en nuestro medio por su costo y fácil acceso. Se comporta como una masa hipoecogénica ovoidea bien definida localizada en el espacio inter-metatarsiano proximal a las cabezas metatarsianas (Figura 2 a,b). La tumoración se localiza en el punto de bifurcación del nervio interdigital. Se ha reportado que la sensibilidad del US en la detección del neuroma de Morton alcanza el $96-100 \%$ y la especificidad es de $83-95 \%{ }^{(4)}$.

En RM, la lesión se localiza centrada en el paquete neurovascular del espacio intermetatarsiano, en situación plantar al ligamento metatarsiano. Su señal en T1 en similar a la del músculo y menor a la señal de la grasa en T2 lo que refleja su contenido rico en colágeno por la fibrosis. Con la inyección de Gadolinio, lo más frecuente es que se encuentre un aumento de la señal de la lesión (Figura 2 c,d).

A 2.- Neuroma Traumático: Corresponde a una proliferación no neoplásica del extremo de un nervio que ha sido cortado parcial o totalmente o que ha resultado lesionado después de un traumatismo o una cirugía. Se presenta como una masa generalmente dolorosa con signo de Tinel positivo. La localización más frecuente es en extremidades que han sufrido una amputación seguido de cabeza y cuello, relacionado con extracciones dentales ${ }^{(2)}$.

Según su presentación se dividen en: 1) Neuroma en Huso (fusiforme) y 2) Neuromas laterales o terminales.

Los Neuromas en Huso son secundarios a fricción o irritación en un tronco neural lesionado sin disrupción. Representan un patrón de curación normal del nervio frente a un traumatismo (Figura 3 a,b,c).

Los Neuromas terminales en cambio, son el resultado de un traumatismo severo con avulsión parcial, disrupción o transección completa del nervio, 

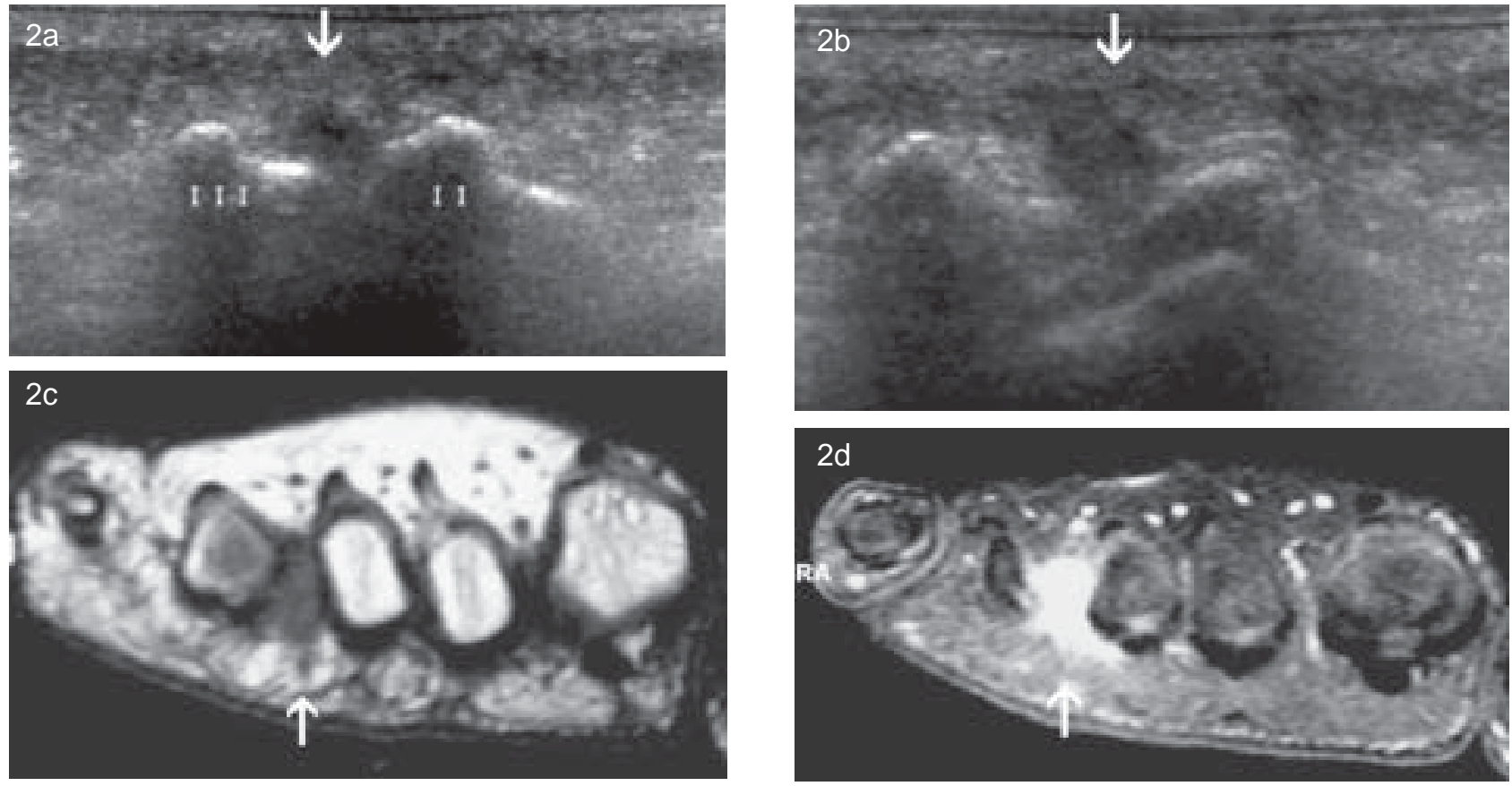

Figura 2 a-d. Neuroma de Morton. a,b: US Corte transversal: masa hipoecogénica entre la cabeza del segundo y tercer metatarsiano (flecha). c: RM T1 corte transversal: masa hipointensa homogénea (flecha). d: RM Gadolinio: aumento de señal de la lesión (flecha).
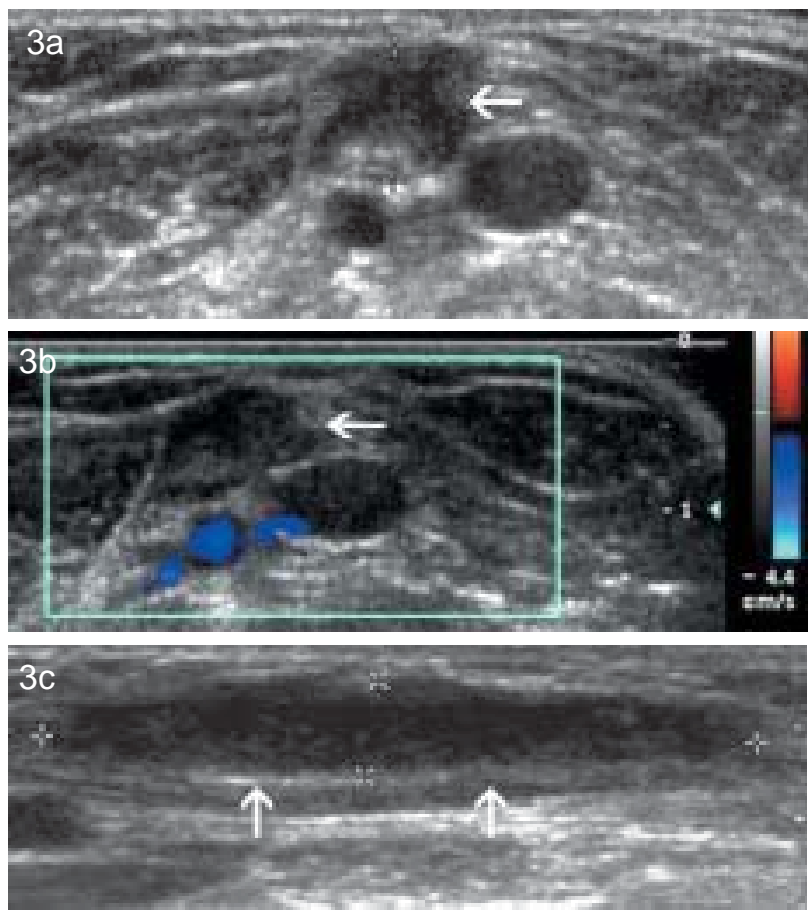

Figura 3 a-c. Neuroma "en huso". a,b: US corte transversal c: US corte longitudinal del nervio mediano a nivel del brazo, aumentado difusamente de diámetro por presencia de masa hipoecogénica (flecha).

generalmente relacionados con amputaciones. Aparecen 1 a 12 meses después de la misma ${ }^{(5)}$.

El diagnóstico por imágenes es útil para la localización de estas lesiones aunque su pesquisa es difícil cuando miden menos de $1 \mathrm{~cm}$. La RM es un excelente método para su detección. Se comporta como una masa hipointensa en T1 y de señal intermedia en T2 con aumento de señal variable después de la inyección de contraste paramagnético. Una limitación de la RM es la presencia de clips o fragmentos metálicos que producen artefactos en la imagen. EI US es una valiosa herramienta alternativa. El Neuroma se identifica como una masa hipoecogénica a veces de aspecto pseudo quístico con márgenes mal definidos.

A 3.- Ganglión de la Vaina neural: Los gangliones intraneurales de nervios periféricos han sido reportados recientemente. Son bastante infrecuentes y afectan en su mayoría a nervios de la rodilla (peroneo común, poplíteo, tibial, siendo el primero el más frecuente $)^{(2,6)}$.

Su origen es debatido; muchos de ellos podrían corresponder a extensión de gangliones provenientes de la articulación tibioperonea con compromiso neural secundario.

Clínicamente se caracterizan por masa palpable con síntomas neurológicos relacionados con la compresión neural.

En TC, US y RM se comportan como una masa quística septada.

A 4. Fibrolipoma neural: También llamado hamartoma fibrolipomatoso neural, lipoma perineural o infiltración grasa neural. Su causa es desconocida. Afecta a hombres y mujeres jóvenes que generalmente consultan por aumento de volumen en el aspecto volar de la muñeca y antebrazo ya que su localización más frecuente es el nervio mediano. También se presentan con síntomas propios del síndrome del túnel del carpo. En algunos casos, se presenta asociado a macrodactilia, en el cuadro 
denominado "Macrodistrofia Lipomatosa"(2) Esta entidad compromete usualmente el dedo índice y medio de la mano y el pie. El nervio digital correspondiente aumenta de volumen difusamente por infiltración del epineuro y perineuro por tejido fibroadiposo. El tejido adiposo rodea y separa los fascículos nerviosos.

En la Rx simple encontramos aumento desproporcionado de los elementos óseos y tejido blando en los dedos afectados. En RM, se demuestra la infiltración grasa del nervio (Figura 4 a,b,c).

A 5.-Tumores de vaina neural: Son lesiones neoplásicas benignas que se dividen en dos grupos morfológicos que tienen distintas características histopatológicas ellos son el Schwannoma (también llamado neurilemmoma o neurinoma) y neurofibroma.

A 5 a.- Schwannoma: Constituye aproximadamente un $5 \%$ de las neoplasias benignas de los tejidos blandos ${ }^{(2,7)}$. Compromete raíces espinales y simpáticas en cabeza y cuello, superficie flexora de extremidades superiores e inferiores (especialmente nervios cubital y peroneo), mediastino y retroperitoneo. No tiene predilección por sexo. Afecta a pacientes entre 20 y 40 años. Usualmente son solitarios, menores de $5 \mathrm{~cm}$ al momento del diagnóstico, de crecimiento lento, móviles a la palpación, generalmente asintomáticos, excepto cuando son de gran tamaño en que pueden presentarse con dolor. De morfología fusiforme y habitualmente excéntricos en relación al eje del nervio ${ }^{(1,2)}$. Rara vez se asocian a neurofibromatosis. Histológicamente presentan áreas celulares (Antoni A) y áreas hipocelulares (Antoni B), con alto contenido mixoide, lo que se correlaciona con su aspecto imagenológico.

EI US puede ser utilizado como herramienta diagnóstica única cuando se demuestra la continuidad de lesión con un nervio, (Figura 11) lo que produce un aspecto patognomónico caracterizado por una masa sólida fusiforme, hipoecogénica, a veces heterogénea, vascularizada, bien definida y excéntrica al eje del nervio (Figura 5). Si no es posible demostrar la continuidad de la masa con la estructura neural, es útil la RM en que encontraremos una masa de similares características (sólida, vascularizada, heterogénea) con signos propios de las neoplasias de vaina neural: el signo "target" que refleja la heterogeneidad de la lesión ya que el centro de la misma se comporta hipointenso y la periferia hiperintensa en secuencias potenciadas en T2 y el signo "split fat" o desplazamiento graso, que como su nombre lo indica, corresponde a una separación o desplazamiento de la grasa vecina a la tumoración (Figuras 5 y 6 ).

Estos dos signos son compartidos con el Neurofibroma. Un hecho diferencial es la presencia de degeneración quística que es mucho más frecuente en el Schwannoma que en el Neurofibroma ${ }^{(7)}$.
A 5 b.- Neurofibroma: Representa aproximadamente el $5 \%$ de las neoplasias benignas de los tejidos blandos. Se presenta con igual frecuencia en hombres y mujeres. Hay 3 tipos: Localizado, difuso y plexiforme.

La forma localizada es la más común $(90 \%$ de los casos). La gran mayoría son solitarios y no asociados a Neurofibromatosis o enfermedad de Von Recklinghausen ${ }^{(1,2,7)}$ (Figuras 7 y 8 ).

La Neurofibromatosis es una displasia mesodérmica que afecta múltiples órganos y sistemas. La tríada clínica clásica para su diagnóstico es: lesiones cutáneas, deformidades esqueléticas y deficiencia mental (Figuras 9 y 10).

En US se presenta como masa hipoecogénica bien definida, a veces con refuerzo posterior del sonido, con signo de target ecográfico (centro hiperecogénico, periferia hipoecogénica).

En RM se comporta similar a los schwannomas con menor tendencia a la degeneración quística y por lo general no se localizan en forma excéntrica en relación al eje del nervio.

En TC aparece como una masa hipodensa relativa al músculo que se realza tras la inyección de medio de contraste(7) (Figura 12).

La forma difusa afecta a niños y adultos jóvenes. Compromete el tejido subcutáneo de cabeza y cuello. Generalmente son lesiones aisladas y no asociadas a Neurofibromatosis ${ }^{(2,9)}$. En RM se comportan como una masa homogénea, hipointensa o isointensa al músculo en T1 e hiperintensa en T2 que gana señal tras la inyección de Gadolinio (Figura 13).

La forma plexiforme se considera patognomónica de Neurofibromatosis tipo I. Representa el compromiso difuso de un tronco neural y sus ramas. El desarrollo de este tipo de lesiones ocurre principalmente durante la niñez y precede la aparición de Neurofibromas cutáneos. Desde el punto de vista patológico, representa el compromiso difuso de un largo segmento neural y sus ramas, determinando una expansión "tortuosa". Se le ha dado el nombre de "Bolsa de gusanos", por su aspecto imagenológico(2,7) (Figuras 14,15).

Por su gran tamaño, estas lesiones se extienden más allá del epineuro, hacia el tejido adyacente.

Los neurofibromas plexiformes pueden estar asociados con el crecimiento masivo y deformante de una extremidad. A esta condición de le denomina Elefantiasis Neuromatosa ${ }^{(8)}$. Puede acompañarse de hipertrofia de los elementos óseos debido a la hiperemia crónica (Figura 16).

\section{B - Tumores malignos \\ B.1-Tumor maligno de vaina neural}

También llamado neurofibrosarcoma, sarcoma neurogénico ó Shwannoma maligno. Representa cerca de un $6 \%$ de las neoplasias malignas de tejidos blandos $^{(1,7)}$. 

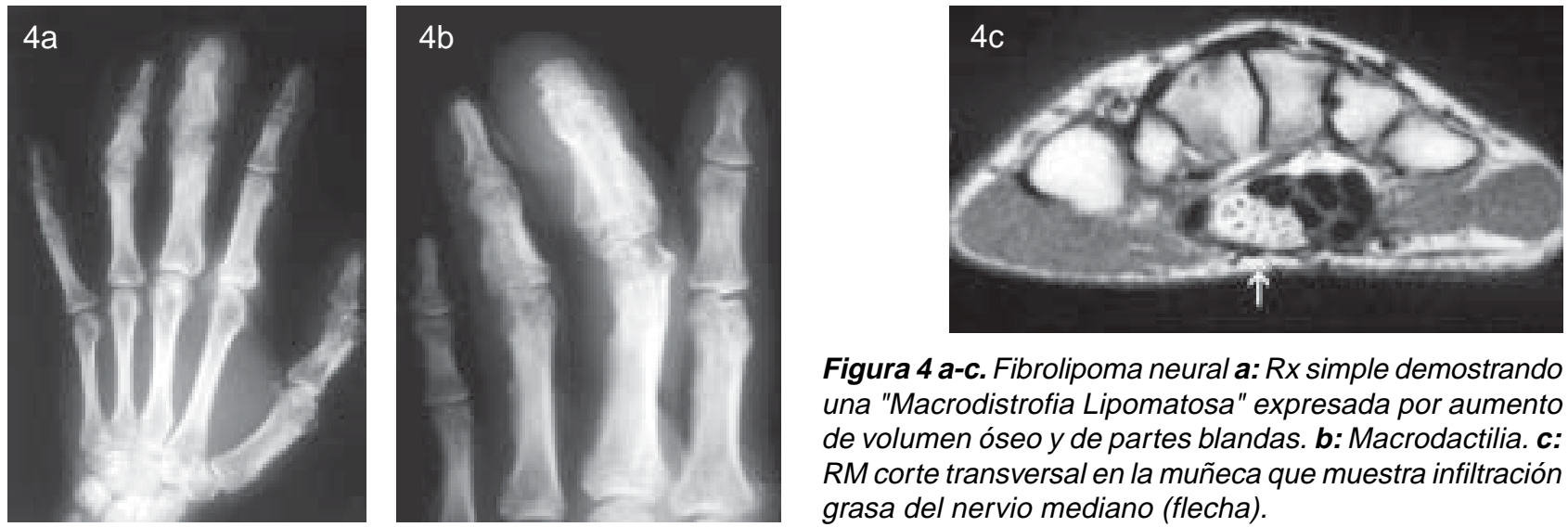

Figura 4 a-c. Fibrolipoma neural a: $R x$ simple demostrando una "Macrodistrofia Lipomatosa" expresada por aumento de volumen óseo y de partes blandas. b: Macrodactilia. c: RM corte transversal en la muñeca que muestra infiltración grasa del nervio mediano (flecha).
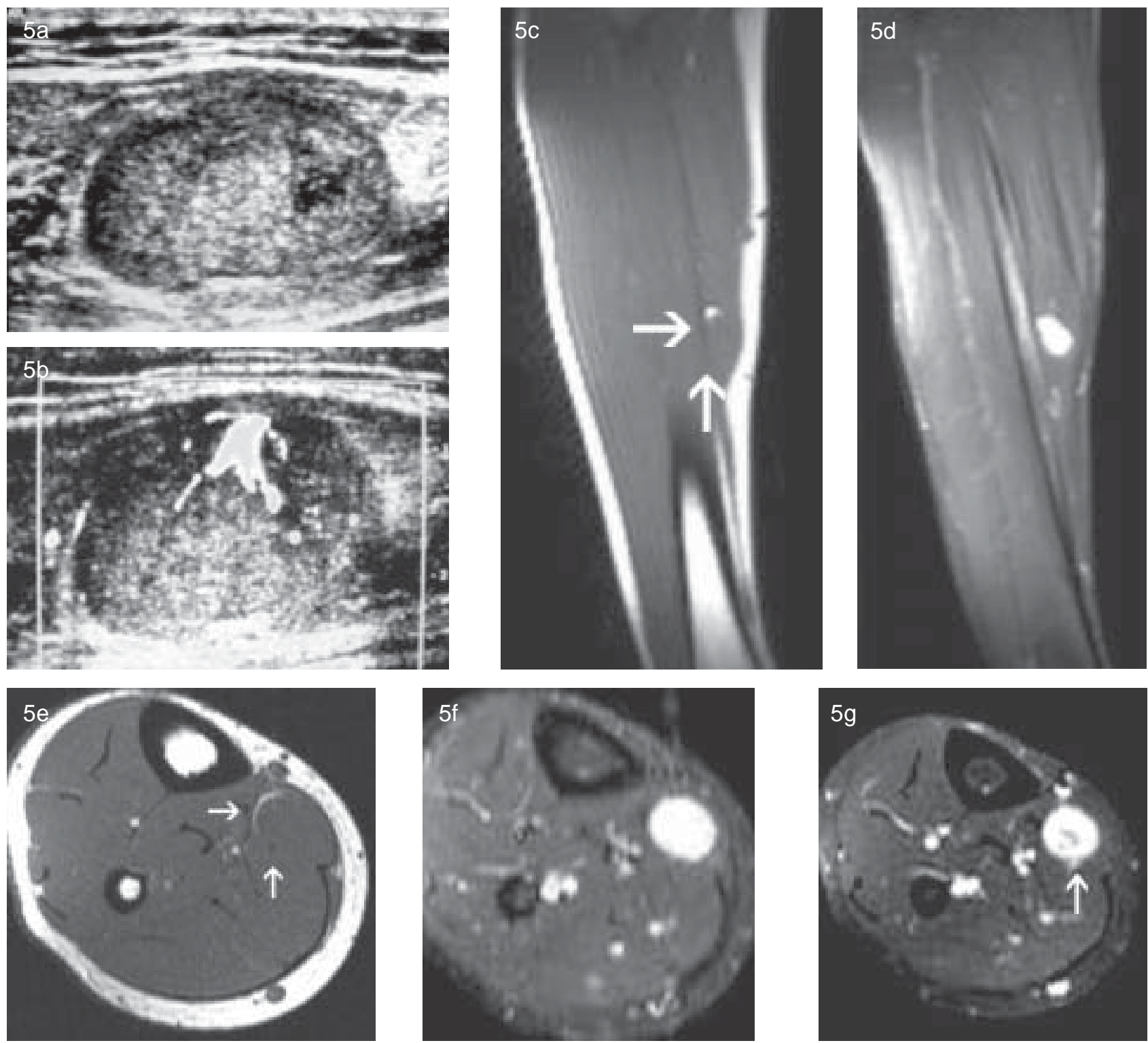

Figura 5 a-g. Schwannoma intramuscular gemelar. a,b: US masa hipoecogénica sólida y vascularizada intragemelar. (Gentileza Dr. J. Mac Kinnon) c: RM corte sagital T1. Masa isointensa al músculo con signo de desplazamiento de la grasa "split fat" (flechas) d: RM corte sagital DP con saturación de la grasa. Masa hiperintensa homogénea. e: RM corte transversal en T1. Masa isointensa al músculo con signo "split fat".(flecha) f: RM corte transversal T2 con saturación de la grasa. Masa hiperintensa homogénea. g: RM con Gadolinio. Masa vascularizada, sólida, heterogénea con centro hipointenso "signo target".(flecha) 

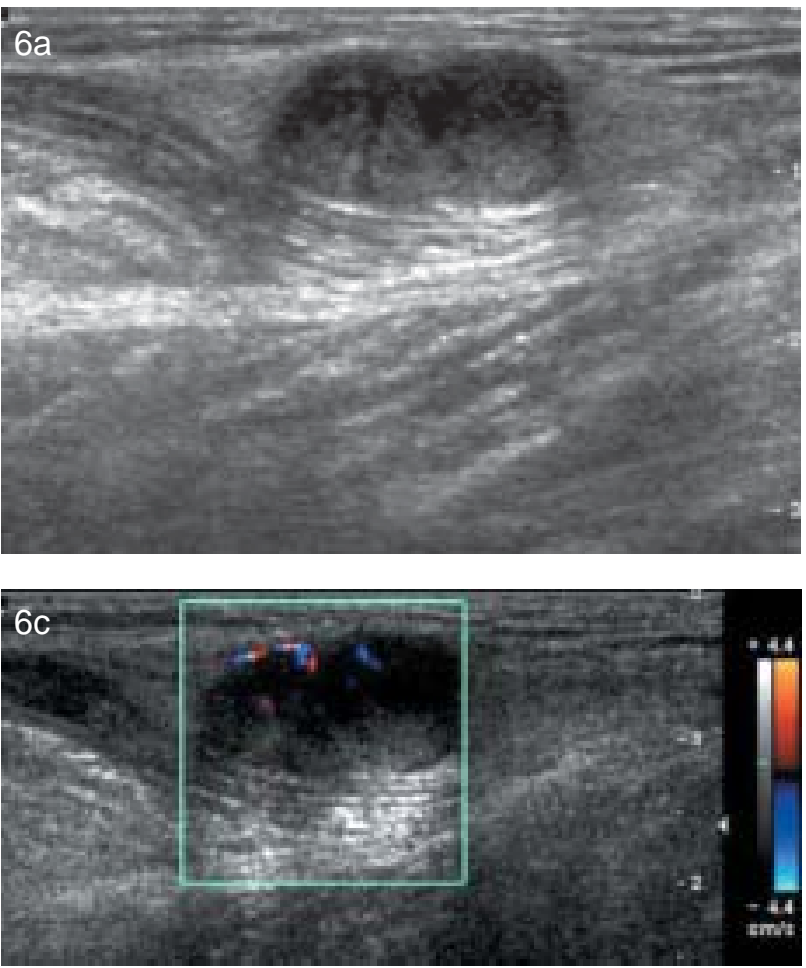

Figura 6 a-c. Schwannoma intramuscular gemelar. a: US masa hipoecogénica intramuscular en gemelo. Hay desplazamiento de fibras musculares vecinas. b: US Corte transversal. c: US Lesión vascularizada.
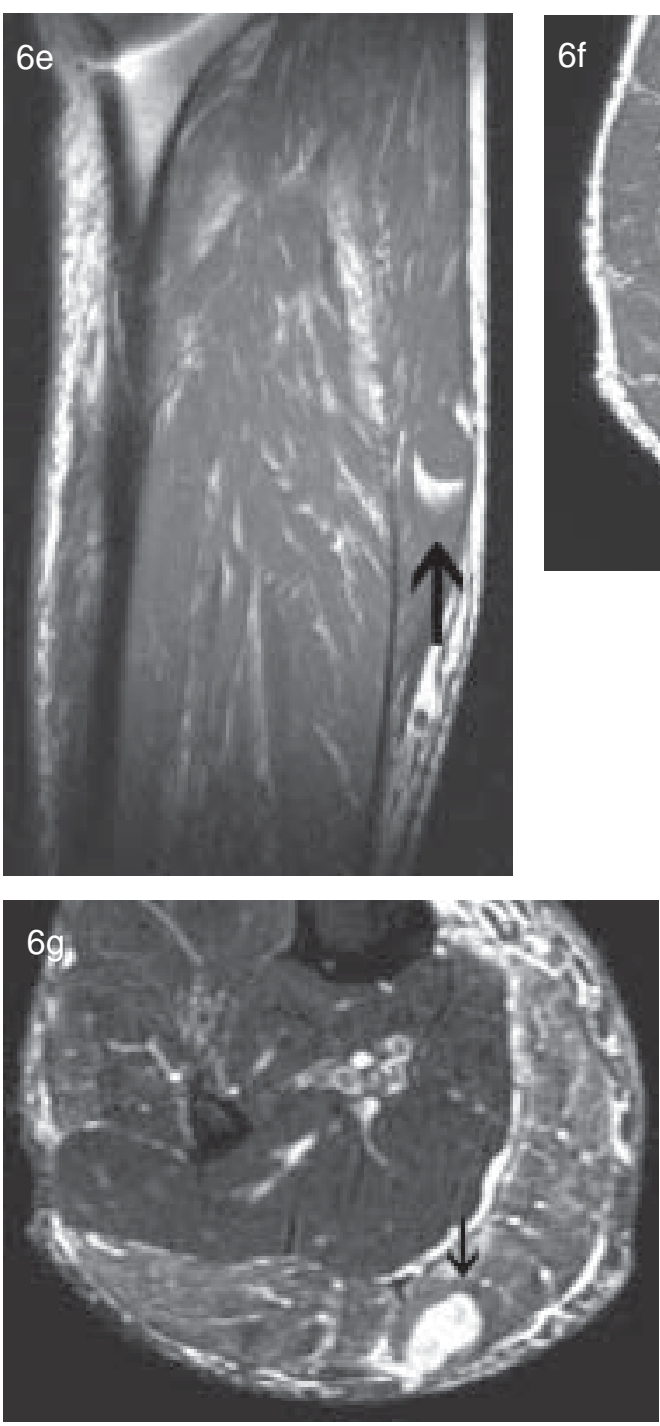
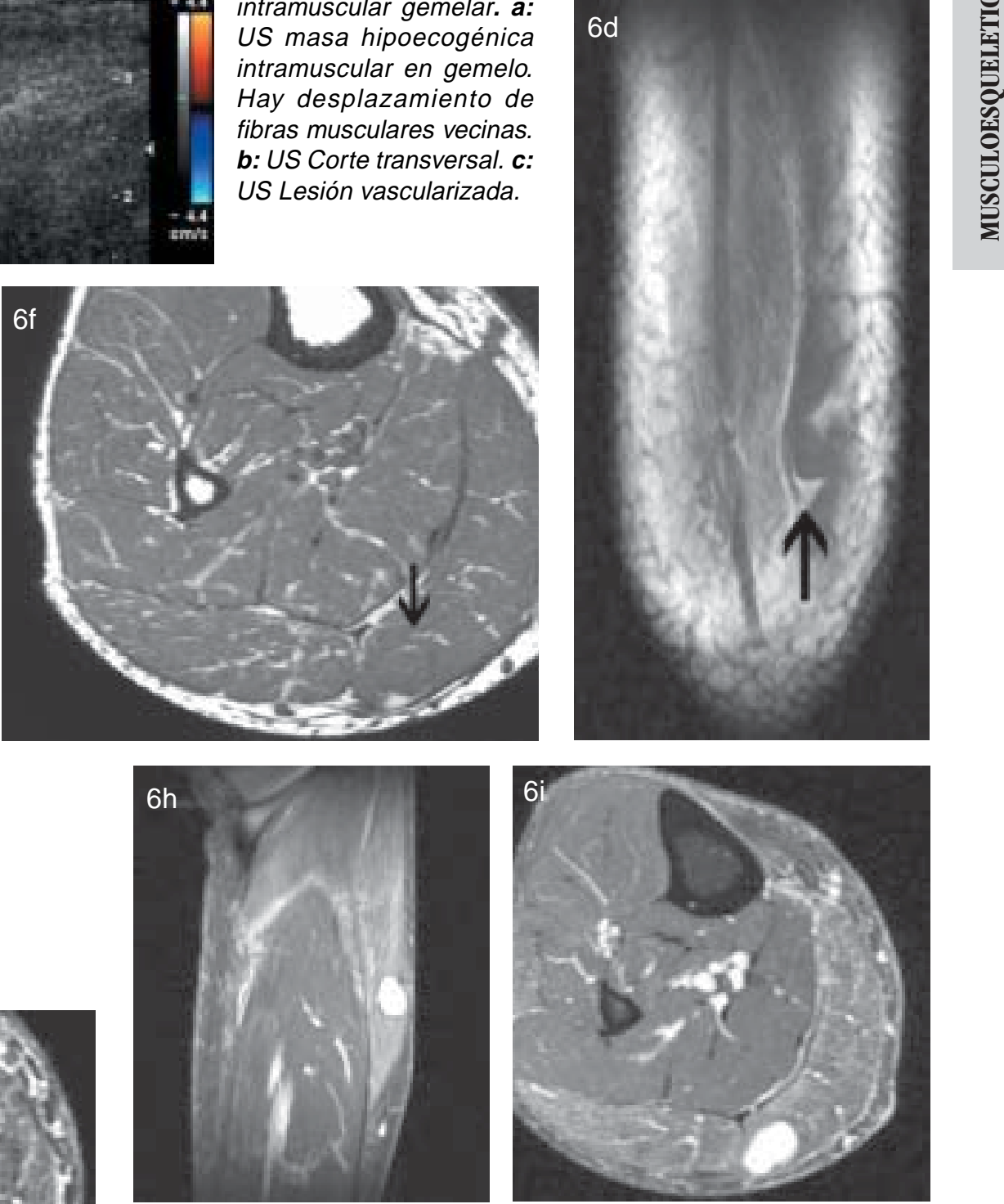

Figura 6 d-i. Schwannoma intramuscular gemelar. d-f: RM T1 sagital. (d) y Coronal (e) y axial (f). Se demuestra una masa isointensa al músculo con signo de desplazamiento de la grasa vecina (flechas). $g$ : RM T2 con saturación de la grasa. Masa hiperintensa heterogénea con centro hipointenso "signo Target" (flecha). h,i: RM T1 Sagital (h) y Axial (i) con Gadolinio demostrando aumento de señal. 

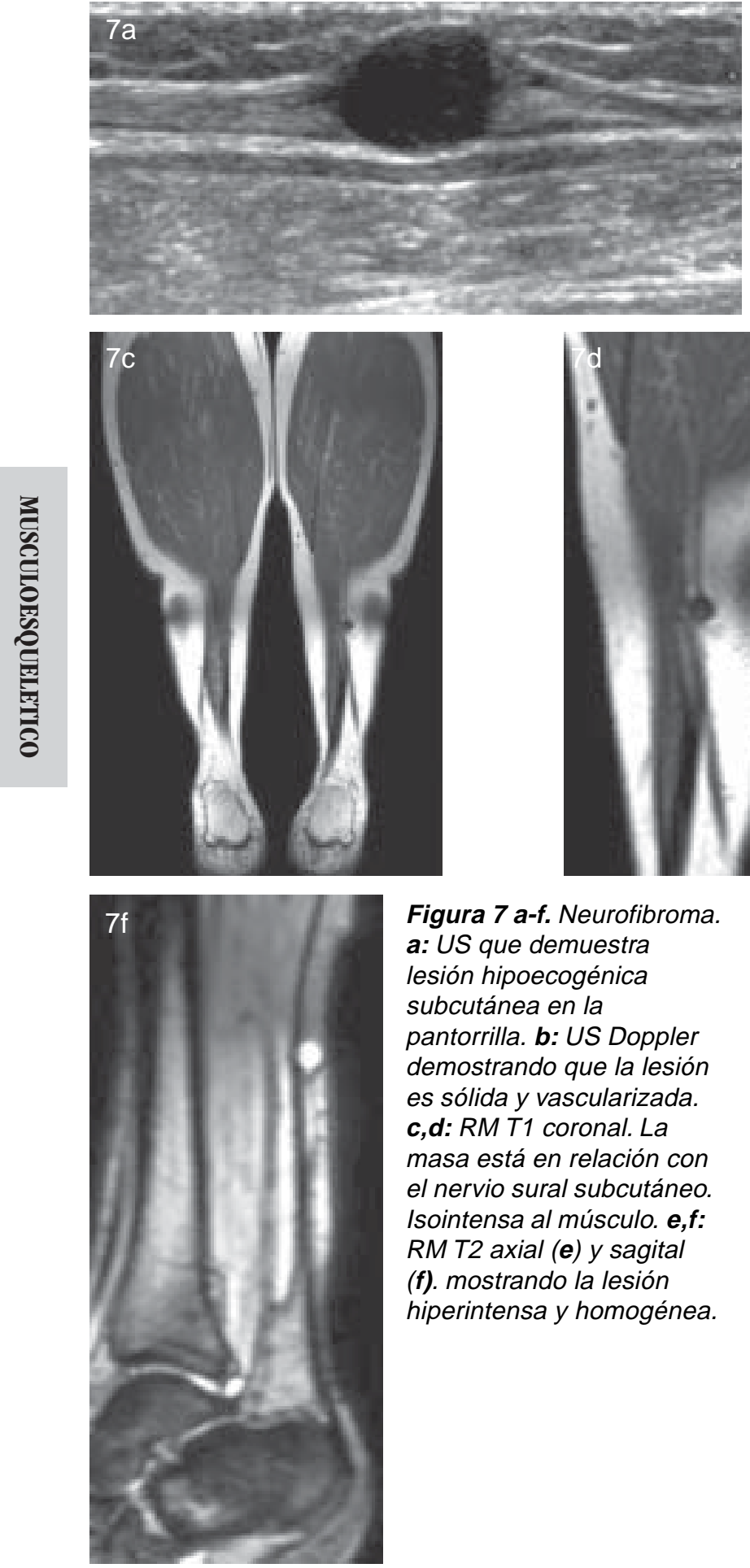

Figura 7 a-f. Neurofibroma. a: US que demuestra lesión hipoecogénica subcutánea en la pantorrilla. b: US Doppler demostrando que la lesión es sólida y vascularizada. c,d: RM T1 coronal. La masa está en relación con el nervio sural subcutáneo. Isointensa al músculo. e,f: RM T2 axial (e) y sagital (f). mostrando la lesión hiperintensa y homogénea.

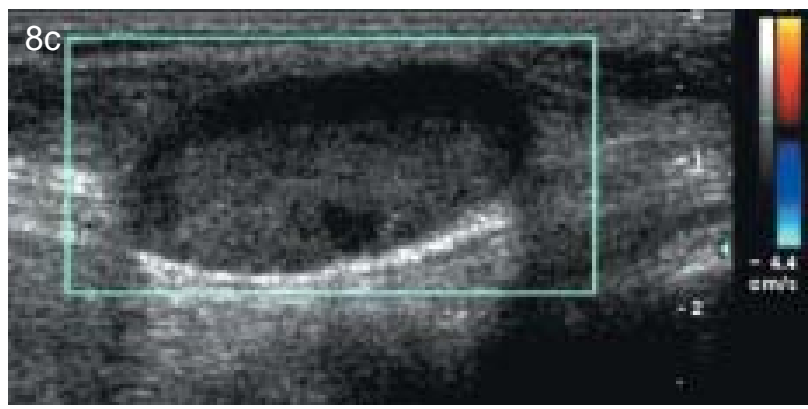

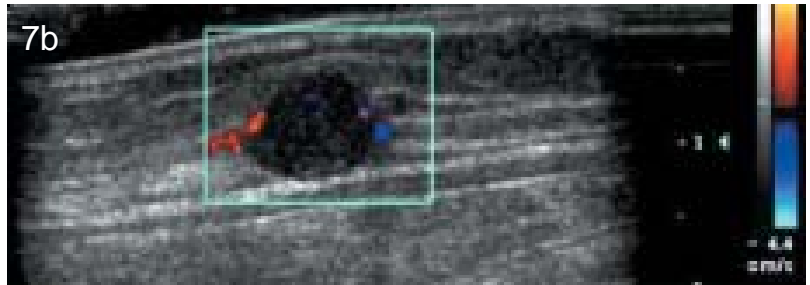
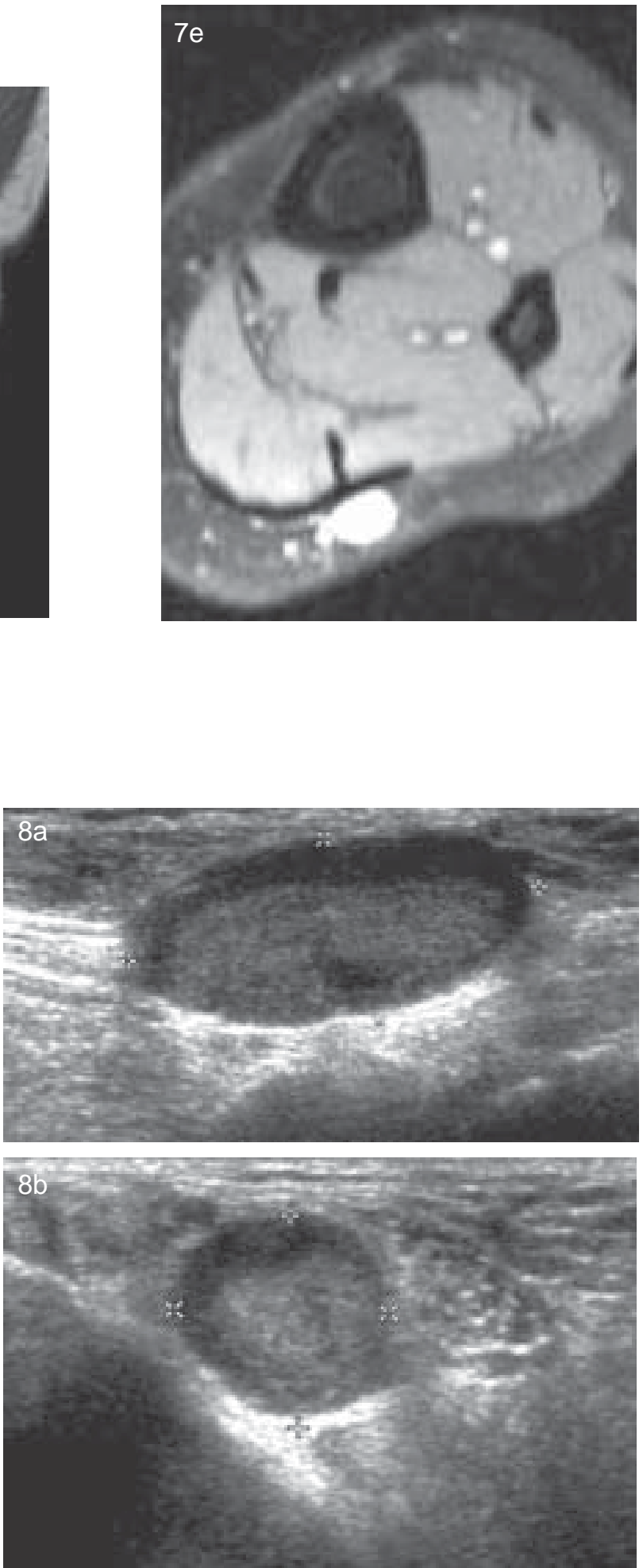

Figura 8 a-c. Neurofibroma del nervio tibial posterior. $\mathbf{a}, \boldsymbol{b}, \boldsymbol{c}$ : US Masa hipoecogénica de aspecto sólido en la cara interna del tobillo. 

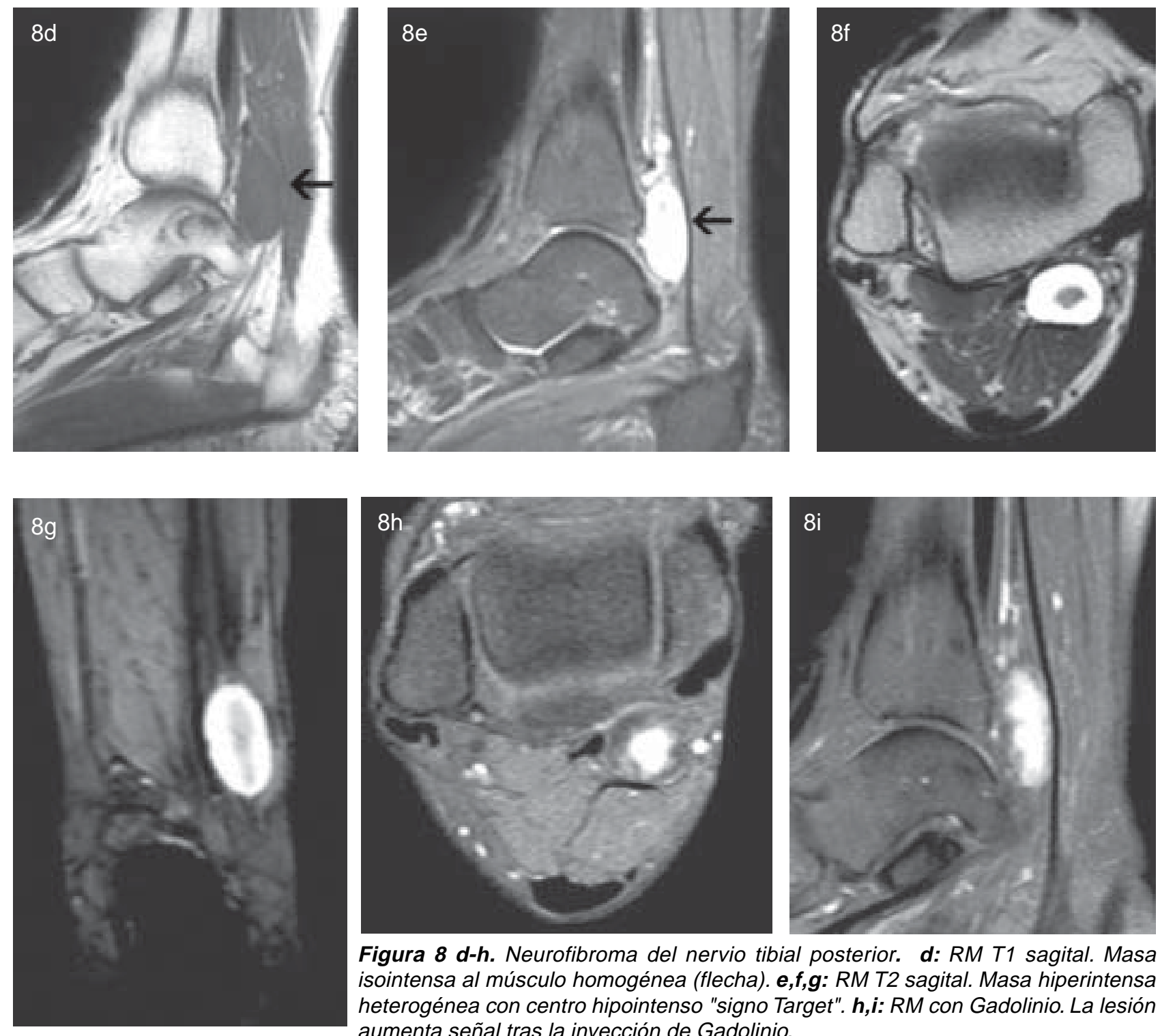

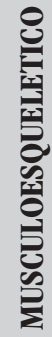

Figura $8 \boldsymbol{d}$-h. Neurofibroma del nervio tibial posterior. d: RM T1 sagital. Masa isointensa al músculo homogénea (flecha). e,f,g: RM T2 sagital. Masa hiperintensa heterogénea con centro hipointenso "signo Target". h,i: RM con Gadolinio. La lesión aumenta señal tras la inyección de Gadolinio.
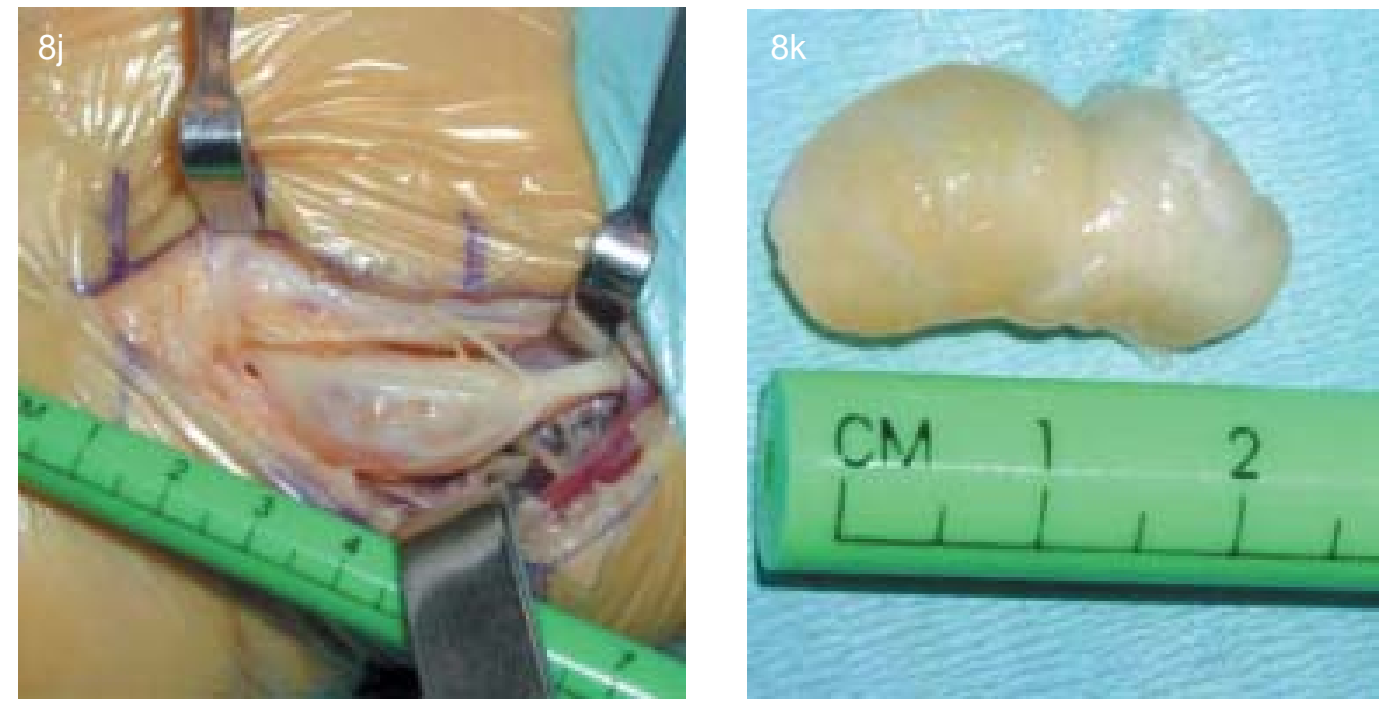

Figura 8 j,k. Neurofibroma del nervio Tibial Posterior. j, k: Pieza quirúrgica. 

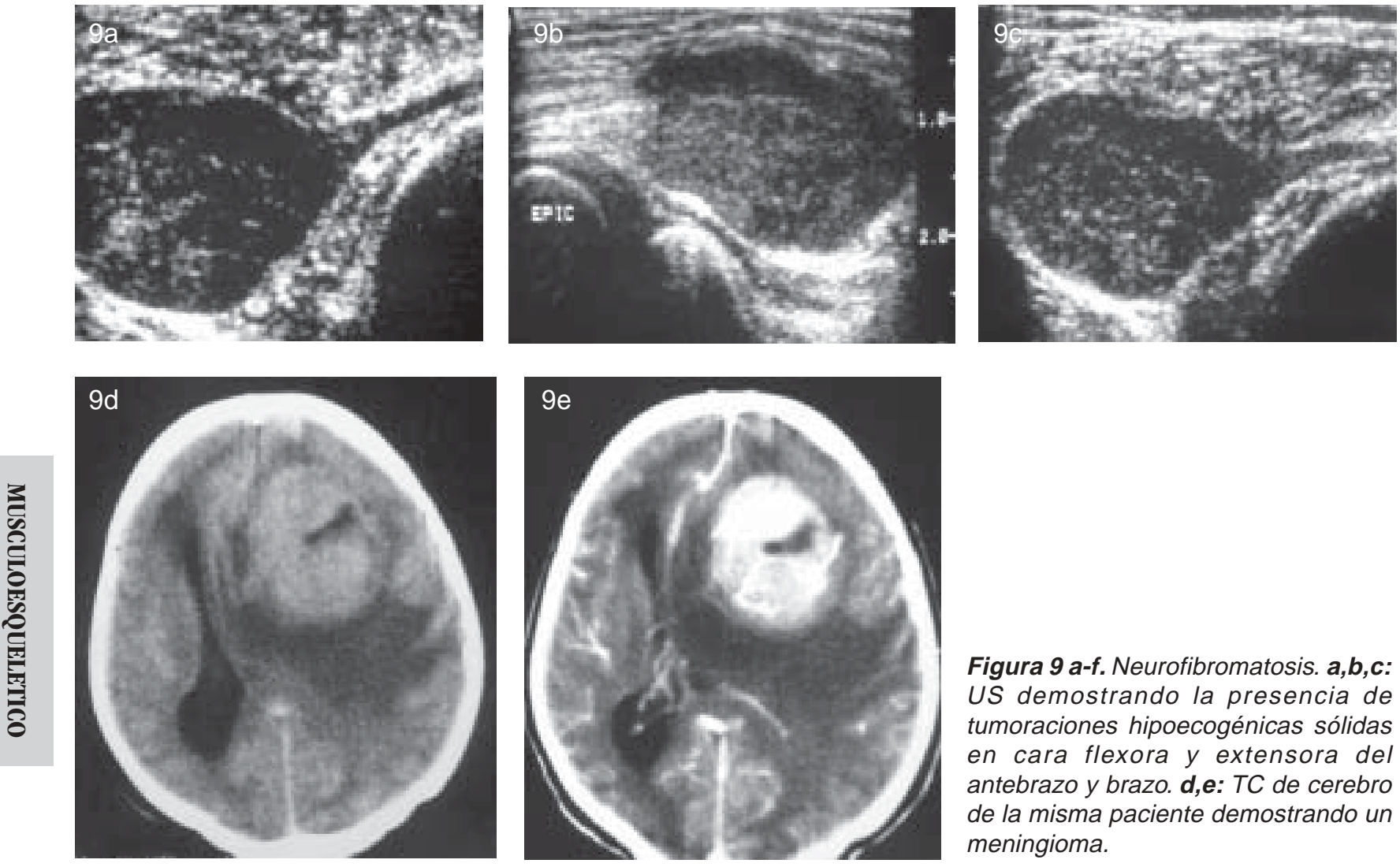

Figura 9 a-f. Neurofibromatosis. $\boldsymbol{a}, \boldsymbol{b}, \boldsymbol{c}$ : US demostrando la presencia de tumoraciones hipoecogénicas sólidas en cara flexora y extensora del antebrazo y brazo. d,e: TC de cerebro de la misma paciente demostrando un meningioma.
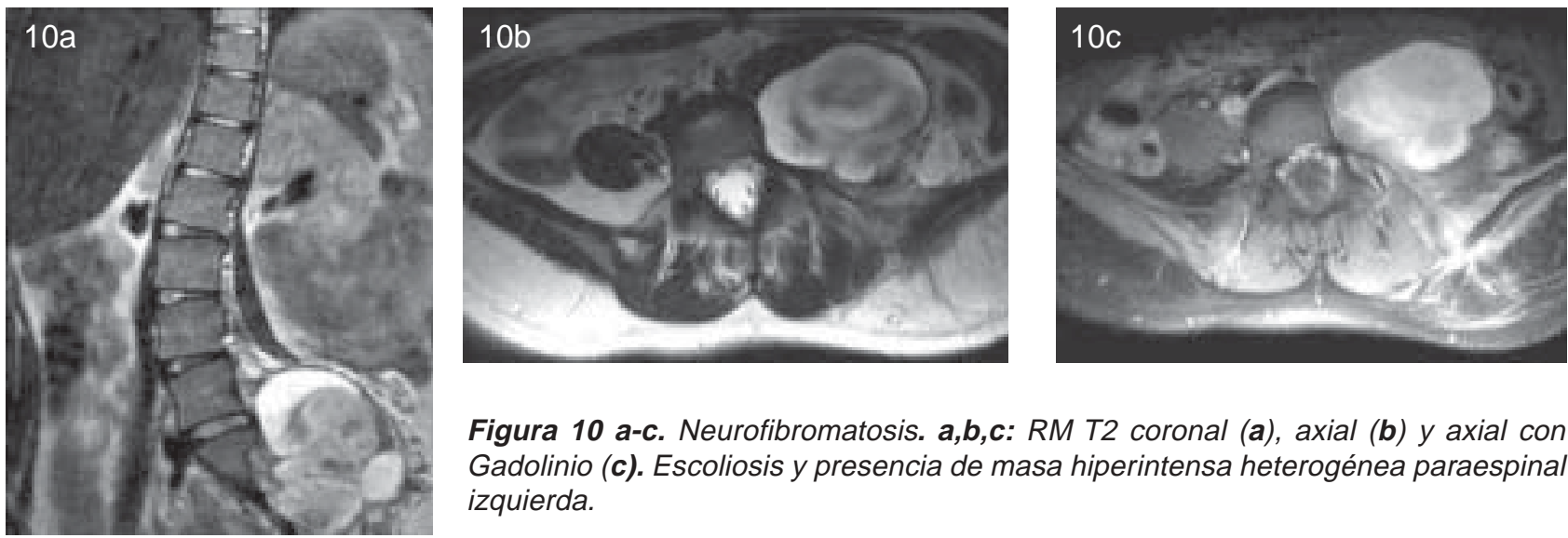

Figura 10 a-c. Neurofibromatosis. a,b,c: RM T2 coronal (a), axial (b) y axial con Gadolinio (c). Escoliosis y presencia de masa hiperintensa heterogénea paraespinal izquierda.
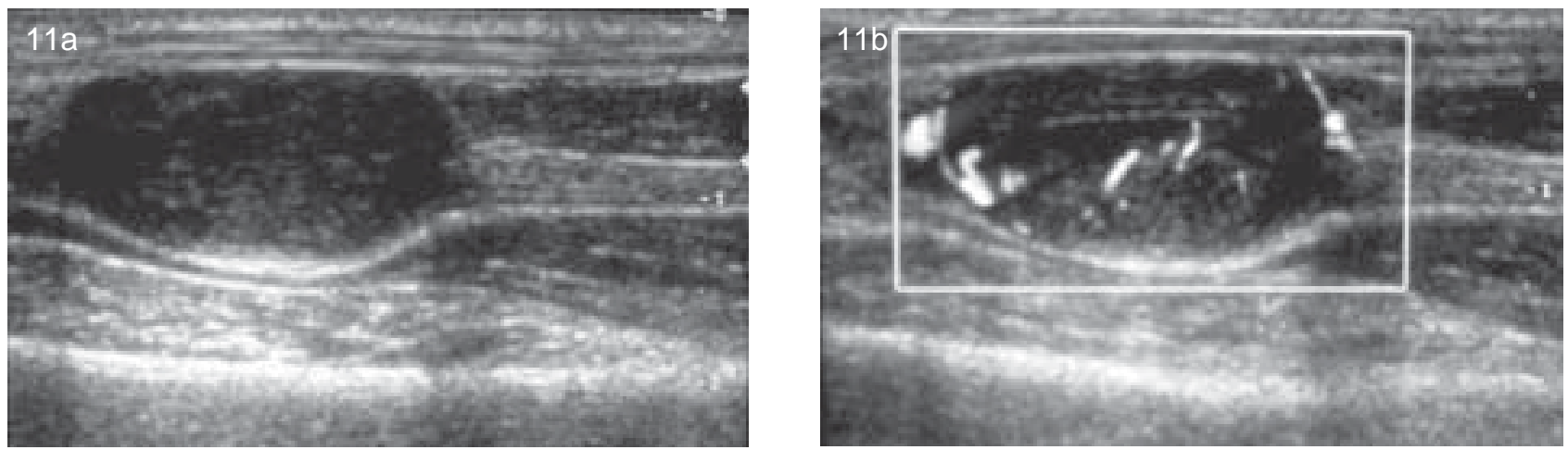

Figura 11. Schwannoma del nervio mediano. a: US corte longitudinal del antebrazo demostrando una masa hipoecogénica en continuidad con el nervio. b: US Doppler color del mismo caso. 

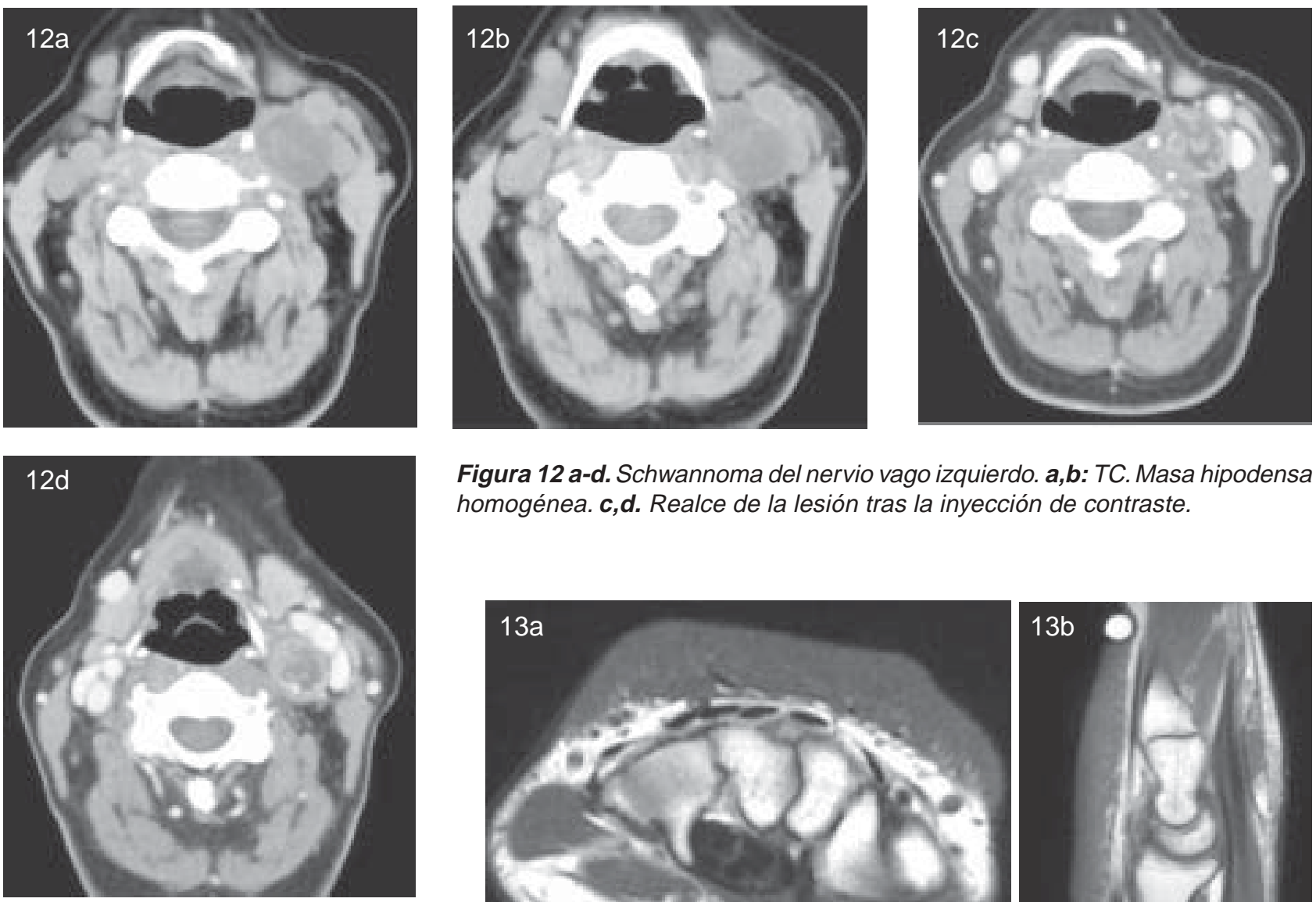

Figura 12 a-d. Schwannoma del nervio vago izquierdo. a,b: TC. Masa hipodensa homogénea. c,d. Realce de la lesión tras la inyección de contraste.
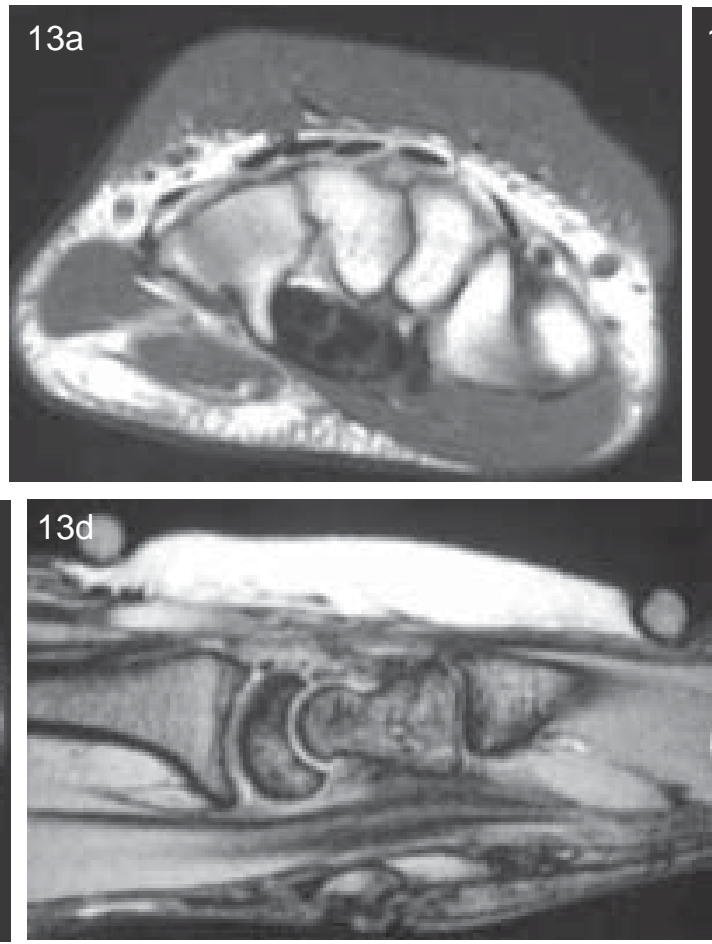

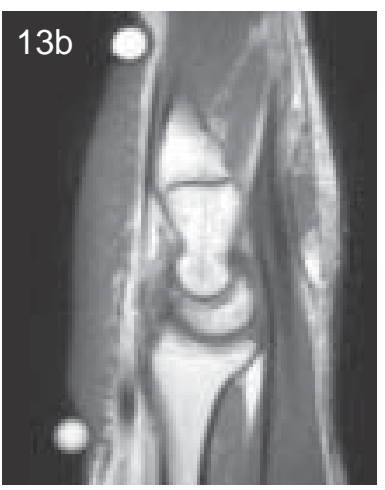

Figura 13 a-d.

Neurofibroma difuso. a,b: RM T1 axial.(a) y sagital (b) Masa isointensa al músculo en situación

subcutánea en la cara extensora de la muñeca. c,d: RM T2 axial (c) y sagital.(d) Masa hiperintensa $y$ homogénea.
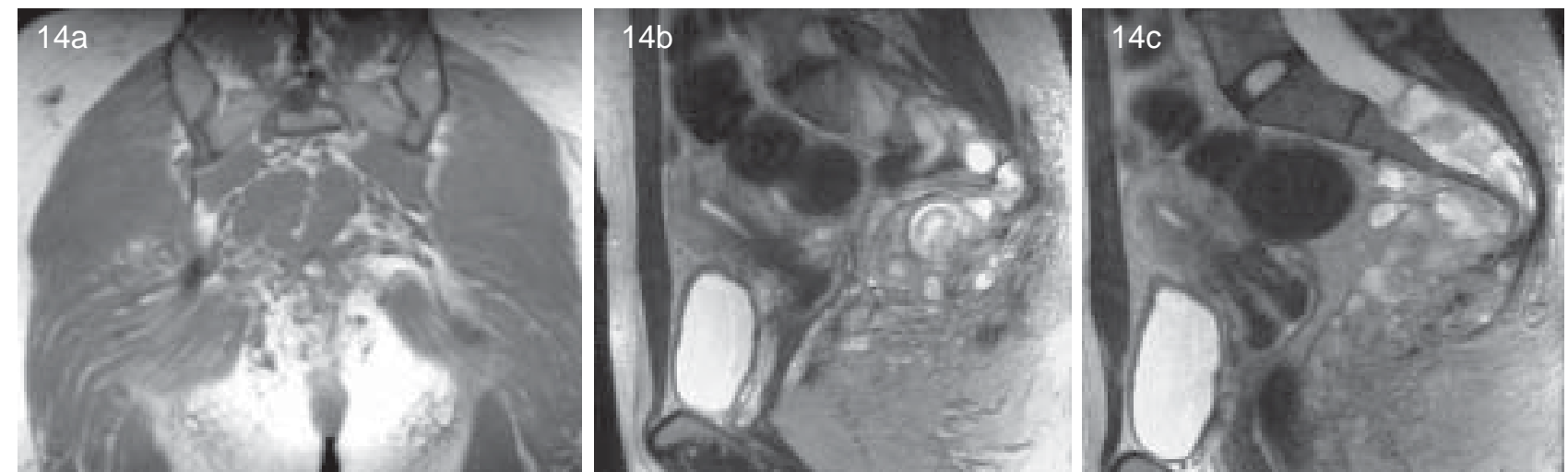

Figura 14 a-c. Neurofibromatosis plexiforme. a: RM T1 coronal. Múltiples masas de pequeño tamaño, isointensas al músculo en proyección del plexo lumbosacro. b,c: RM T2 sagital. 

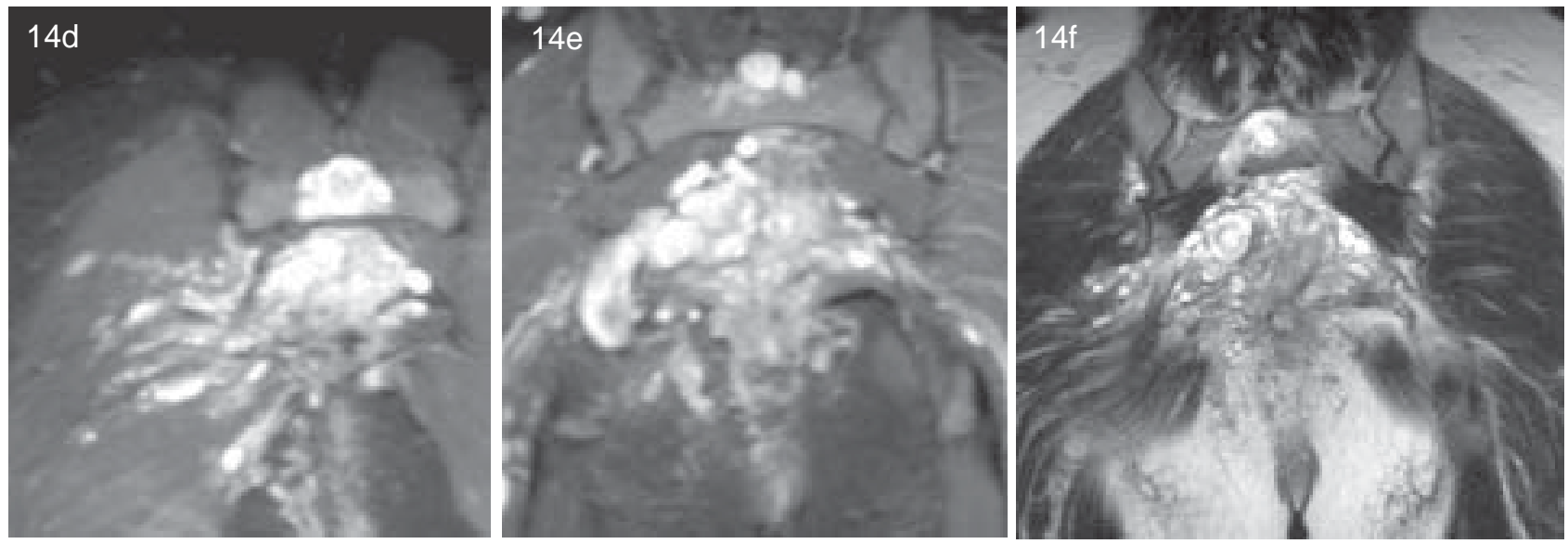

Figura 14 d-g. Neurofibromatosis plexiforme. d,e: RM secuencia STIR coronal. Engrosamiento irregular hiperintenso del plexo lumbosacro. Aspecto de "Bolsa de gusanos". f,g: RM T2 coronal (f) y axial (g).
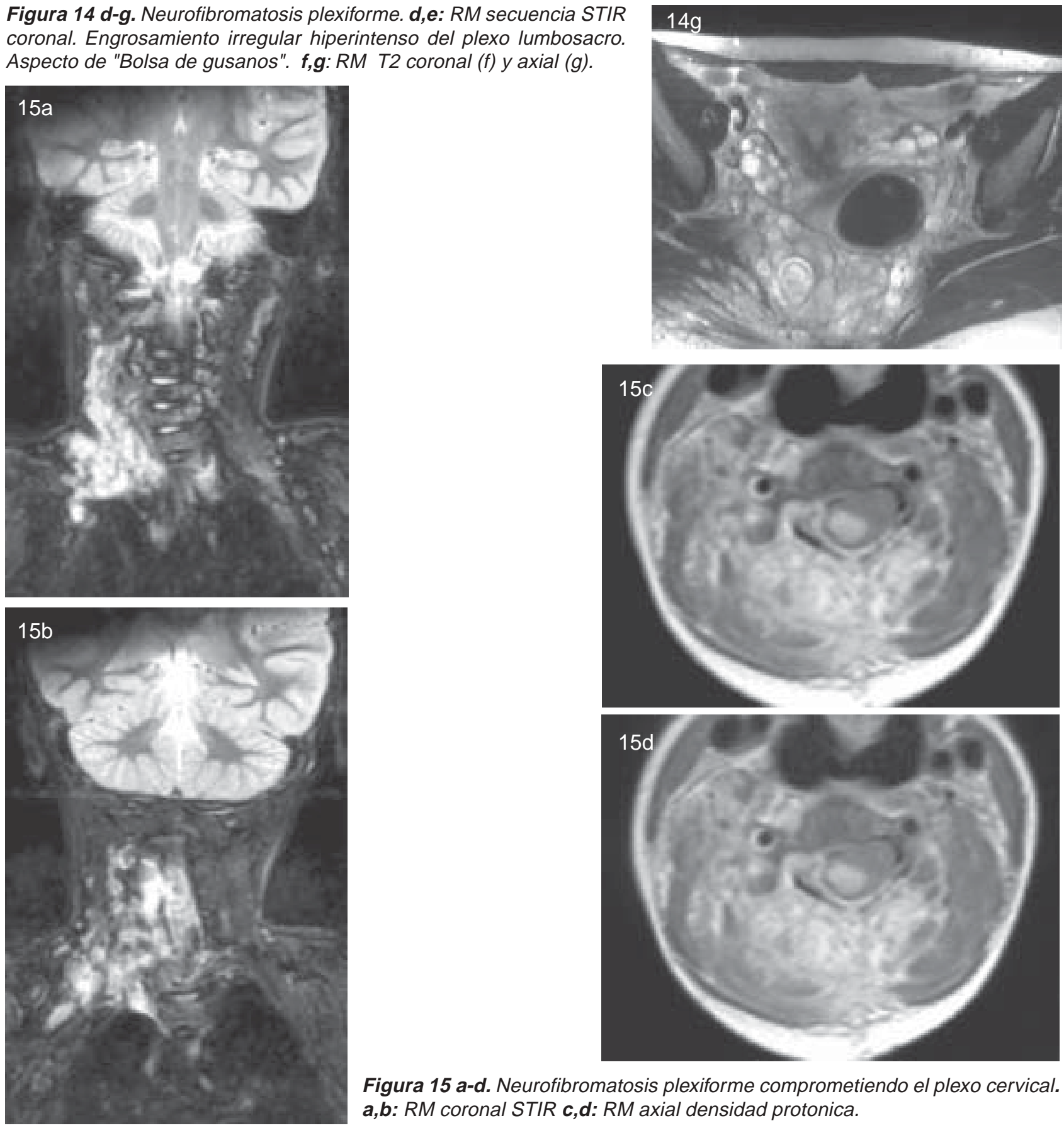

Figura 15 a-d. Neurofibromatosis plexiforme comprometiendo el plexo cervical. a,b: RM coronal STIR c,d: RM axial densidad protonica. 

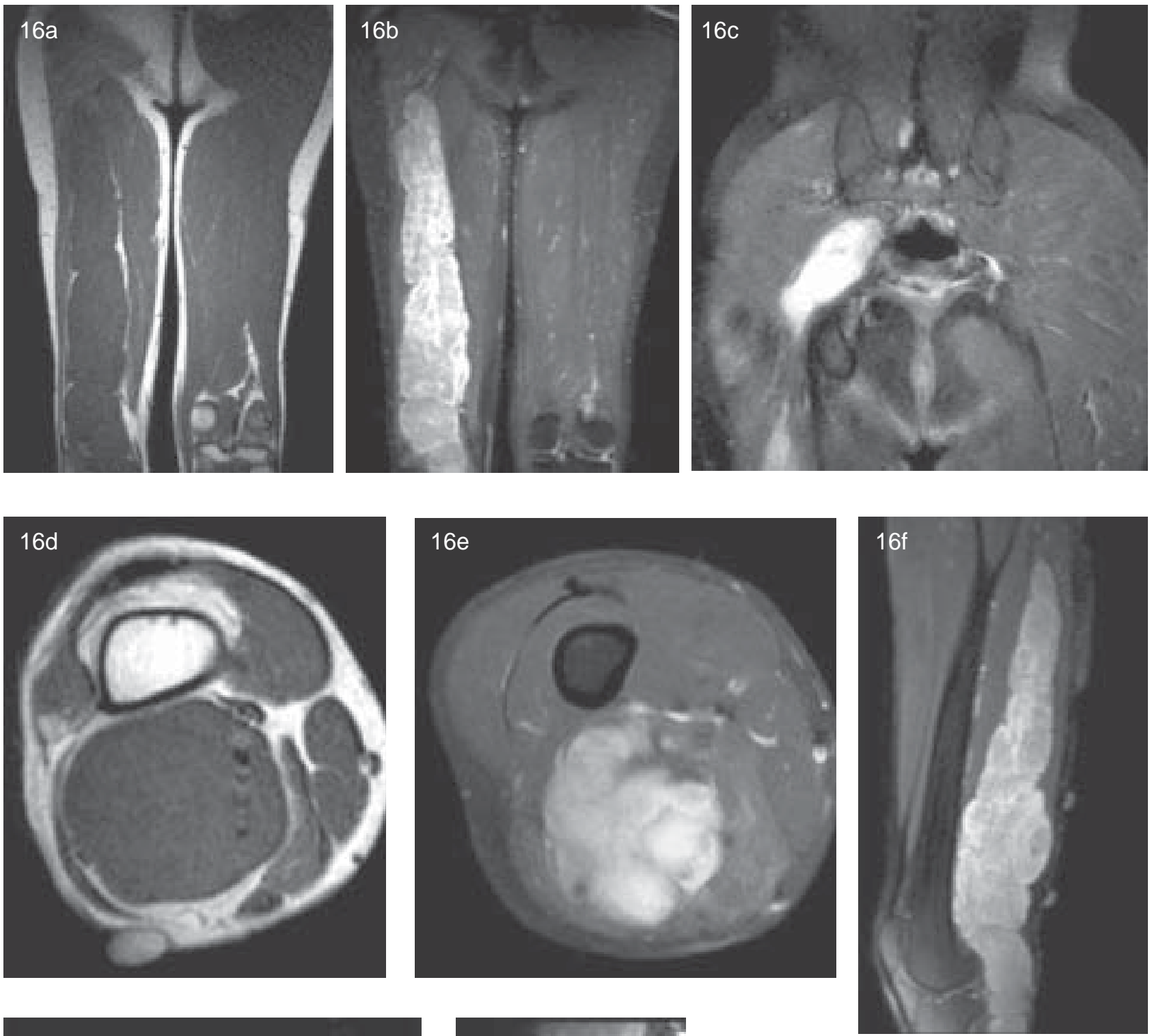

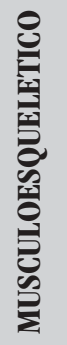
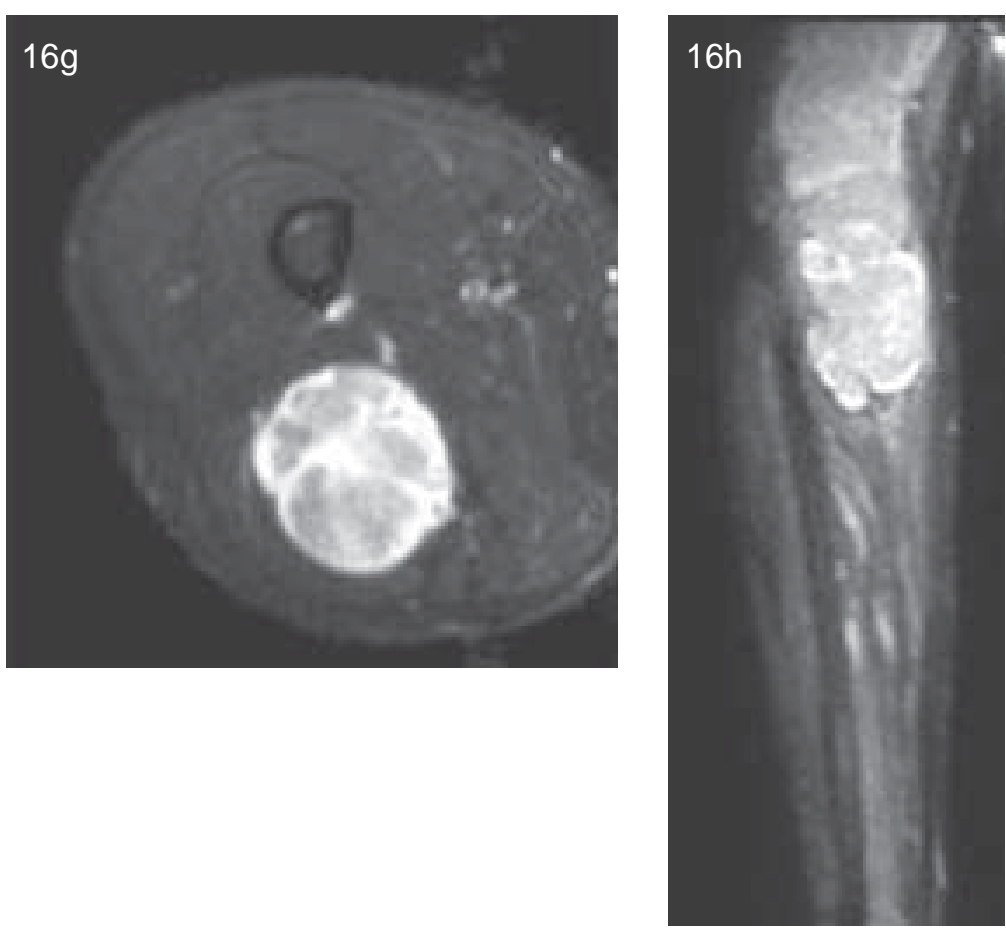

Figura 16 a-h. Neurofibromatosis plexiforme con Elefantiasis Neuromatosa en la extremidad derecha. a: RM T1 coronal. Muestra importante asimetría de los muslos por presencia de masa isointensa al músculo en la región posterior del muslo derecho b: RM T2 con saturación de la grasa demuestra que la masa hiperintensa y heterogénea corresponde al trayecto del nervio ciático. c: RM pelvis T2 coronal: La masa compromete la raíz del ciático. El estudio demuestra otras pequeñas masas en el plexo lumbosacro: $\boldsymbol{d}$ $\boldsymbol{h}$ : Distintos cortes en muslo y pierna mostrando la extensión del compromiso neuromatoso. 
La vasta mayoría se presentan de novo, es decir no asociado a un schwannoma pre-existente y comprometiendo nervios periféricos. En su mayoría, afecta extremidades y tronco. En nervios craneanos, es extremadamente raro. Aproximadamente la mitad está asociado a neurofibromatosis. Además de esta asociación, se sabe poco de la causa de estos tumores. En algunos casos puede encontrarse una asociación con radioterapia previa.

Su presentación clínica es similar a la de otros sarcomas es decir, masa de partes blandas. En el caso de neurofibromatosis hay varios signos clínicos que sugieren la malignización de una lesión como son: cambio en el estado neurológico, dolor, cambio abrupto de tamaño etc.

La forma más frecuente de presentación es como una masa fusiforme o excéntrica propagada a través del epineuro y perineuro de un tronco neural (Figura 17).

Da metástasis a pulmones, hígado, huesos y tejido subcutáneo y su pronóstico es pobre por la alta recurrencia y anaplasia progresiva del tumor.

Imagenológicamente se comporta en forma similar a las neoplasias benignas aunque tienden a ser de mayor tamaño, de márgenes mal definidos, infiltrativos, y heterogéneos ${ }^{(7)}$.

B 2.- Tumor Triton: Corresponde a una variante del Schwannoma maligno que presenta elementos predominantes de Rabdomiosarcoma. Es un tumor raro. Su nombre se debe a la Salamandra Triton que se pensó en un tiempo que era capaz de regenerar músculo estriado a través de la influencia de un nervio normal. Sobre dos tercios de los casos están relacionados con neurofibromatosis. Afecta generalmente a individuos jóvenes.
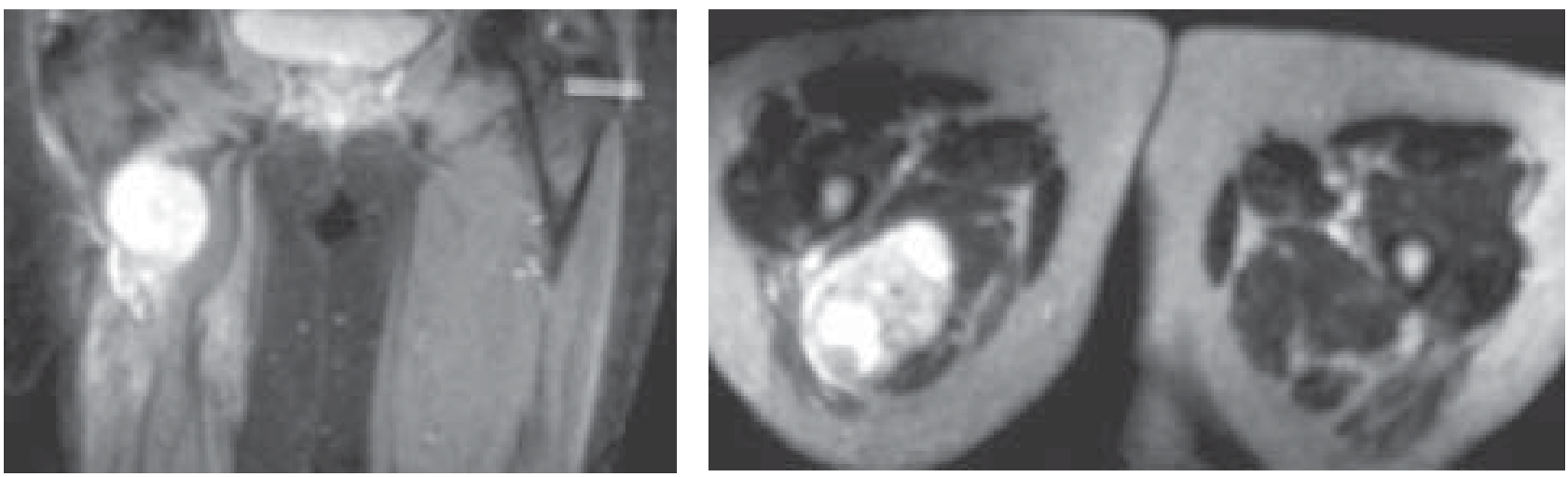

Figura 17 a,b. Schwannoma maligno. RM T2 Corte Coronal (a) y axial (b). Masa hiperintensa heterogénea en el nervio ciático derecho.

\section{Bibliografía}

1. De Schepper A.M. Imaging of soft tissue tumors Springer. Second edition. 2001; 301-330.

2. Murphey M, Smith S, Kransdorf M,Temple T. Imaging of Musculoskeletal Neurogenic Tumors: RadiologicPathologic correlation. Radiographics 1999;19:12531280.

3. Bencardino J, Rosenberg ZS, Beltran J, Liu X, MartyDelfaut E. Morton's Neuroma: is it always syntomatic? AJR 2000; 175:649-653

4. Van Holsbeeck. Musculoskeletal Ultrasound. Introcaso. Mosby Second edition. 2001; 620-625.

5. Henrot $P$, Stines J, Walter F, Martinet $N$, Paysant $J$, Blum A. Imaging of the painful lower limb stump.
Radiographics 2000; 20:219-235.

6. Uetani M, Hashmi K, Hayashi K, Nagatani Y, Narabayashi Y, Imamura K. Peripheral Nerve intraneural ganglion cyst: MR findings in three cases. Journal of Comuter Asistes Tomography 1998; 22(4):629-632.

7. Lin J, Martel W. Cross-Sectional Imaging of peripheral Nerve Sheat Tumors. AJR 2001;176: 75-82.

8. Stevens KJ, Ludman CN, Sully L, Preston BJ. Magnetic Resonance imaging of elephantiasis neuromatosa. Skeletal Radiol 1998; 27:696-701.

9. Peh WCG, Shek TWH, Yip DKH. Magnetic resonance imaging of subcutaneous diffuse neurofibroma. $\mathrm{Br} J$ $\operatorname{Rad} 1997 ; 70: 1180-1183$. 